\title{
Efficacy of Peptide Receptor Radionuclide Therapy for Esthesioneuroblastoma
}

\author{
Olfat Kamel Hasan ${ }^{1-3}$, Aravind S. Ravi Kumar ${ }^{2,4}$, Grace Kong ${ }^{2,4}$, Kira Oleinikov ${ }^{5}$, Simona Ben-Haim ${ }^{6}$, \\ Simona Grozinsky-Glasberg ${ }^{5,6}$, and Rodney J. Hicks ${ }^{2,4}$ \\ ${ }^{I}$ Department of Medicine/Diagnostic Imaging, Hamilton Health Sciences, McMaster University, Hamilton, Ontario, Canada; ${ }^{2}$ Center \\ for Cancer Imaging, Peter MacCallum Cancer Center, Melbourne, Victoria, Australia; ${ }^{3}$ Department of Diagnostic Imaging, Western \\ University, London, Ontario, Canada; ${ }^{4}$ Sir Peter MacCallum Department of Oncology, University of Melbourne, Victoria, Australia; \\ ${ }^{5}$ Neuroendocrine Tumour Unit, ENETS Center of Excellence; and ${ }^{6}$ Department of Nuclear Medicine, Hadassah-Hebrew University \\ Medical Centre, Jerusalem, Israel
}

Esthesioneuroblastoma is rare, with limited therapeutic options when unresectable or metastatic; however, expression of somatostatin receptors qualifies it for peptide receptor radionuclide therapy (PRRT). We report outcomes of PRRT in esthesioneuroblastoma from 2 referral centers. Methods: Using PRRT databases at 2 European Neuroendocrine Tumor Society Centers of Excellence, cases were sought between 2004 and 2018 of patients who had PRRT with recurrent or metastatic esthesioneuroblastoma deemed unsuitable for further conventional therapies. Evaluations of survival and of response using a composite reference standard were performed. Results: Of 7 patients, 4 had partial response, 2 had disease stabilization, and one had early progression. Possible side effects include worsening cerebrospinal fluid leaks. Median progression-free survival was 17 mo (range, 0-30 mo), and median overall survival was $32 \mathrm{mo}$ (range, 4-53 mo). Conclusion: PRRT shows promising efficacy and moderate survival duration in unresectable locally advanced or metastatic esthesioneuroblastoma warranting larger cohort studies incorporating measures of quality of life.

Key Words: esthesioneuroblastoma; peptide receptor radionuclide therapy; lutetium-177 DOTATATE

J Nucl Med 2020; 61:1326-1330

DOI: $10.2967 /$ jnumed.119.237990

$\mathbf{E}$ thesioneuroblastoma, which is also known as olfactory neuroblastoma, is a rare malignancy (incidence, 0.4 per million) accounting for $3 \%-6 \%$ of intranasal neoplasms $(1,2)$. The pathology of esthesioneuroblastoma is intermediate between a pure neural neoplasm, such as neuroblastoma or paraganglioma, and an epithelial tumor with neuroendocrine differentiation (3). The Hyams histologic grading system comprises 4 grades ranging from well differentiated (I) to least differentiated (IV) (4). The clinical staging system introduced by Kadish and modified by Morita $(5,6)$ is a good predictor of outcomes $(5,7,8)$. Stage A is confined to the nasal cavity, stage $\mathrm{B}$ extends to the paranasal sinuses, stage $\mathrm{C}$ involves further local extension, and stage D includes nodal or distant metastases.

Received Nov. 13, 2019; revision accepted Jan. 10, 2020.

For correspondence or reprints contact: Olfat Kamel Hasan, Hamilton Health Sciences, 1280 Main St. W., Hamilton Ontario L8S 4L8, Canada.

E-mail: kamelhasan@hhsc.ca

Published online Jan. 31, 2020.

COPYRIGHT (C 2020 by the Society of Nuclear Medicine and Molecular Imaging.
A metaanalysis by Dulguerov et al. (7) showed that Hyams pathologic grade, nodal metastases, and response to treatment were prognostic. Late recurrences can occur, with a local recurrence rate of $29 \%$, a regional recurrence rate of $16 \%$, and a distant metastasis rate of $17 \%$. Ten-year survival ranges from $52 \%$ to $69 \%(7,8)$.

Standard treatment for local disease is surgery followed by radiation, with or without chemotherapy (9). Options for metastatic disease are limited, with one metaanalysis suggesting a median clinical follow-up of only 9 mo after diagnosis of distant metastatic disease for the cohort (interquartile range, 5-9 mo; range, 0.25$224 \mathrm{mo}$ ) and only 19 patients alive at the last follow-up. The 6-mo overall survival rate after diagnosis of distant metastases was $63 \%$ (95\% confidence interval, 51\%-77\%), and 2-y survival for patients receiving multimodality treatment was $63 \%$ (95\% confidence interval, $43 \%-92 \%$ ) (10). A potential molecular target for esthesioneuroblastoma is overexpression of cell surface somatostatin receptors (SSRs) $(11,12)$. Somatostatin analogs bind to SSRs with high affinity, enabling theranostic applications. PET/CT with ${ }^{68} \mathrm{Ga}$-labeled somatostatin analogs can be used to image the density of SSR expression at disease sites, and therapy can be performed with a companion therapeutic pharmaceutical such as ${ }^{177} \mathrm{Lu}$-DOTATATE for peptide receptor radionuclide therapy (PRRT) $(13,14)$. There is high-level evidence for PRRT in unresectable gastroenteropancreatic neuroendocrine tumors $(15,16)$, but data on rarer forms of neuroendocrine neoplasia are limited, with only very scarce data regarding esthesioneuroblastoma.

We describe the outcomes of 7 patients with recurring or metastatic esthesioneuroblastoma who received PRRT with or without radiosensitizing chemotherapy from 2 referral centers, which are now accredited within the European Neuroendocrine Tumor Society Centre-of-Excellence Network.

\section{MATERIALS AND METHODS}

We retrospectively reviewed 7 consecutive patients with esthesioneuroblastoma who received PRRT from August 2004 to November 2018. Five patients were treated at the Peter MacCallum Cancer Centre in Melbourne and 2 at Hadassah-Hebrew University Medical Center in Jerusalem. Data were collected until death or the most recent available follow-up.

Eligibility criteria were recurrent unresectable or progressive metastatic disease by imaging or symptoms despite conventional treatment, high SSR expression on SSR imaging (uptake higher than background liver activity), and adequate renal and hematologic function. PRRT was administered with renoprotective amino acid infusion as per unit protocol.

Responses were assessed at 3 mo after PRRT. Clinical response was measured subjectively by the referring physician. Imaging response was 


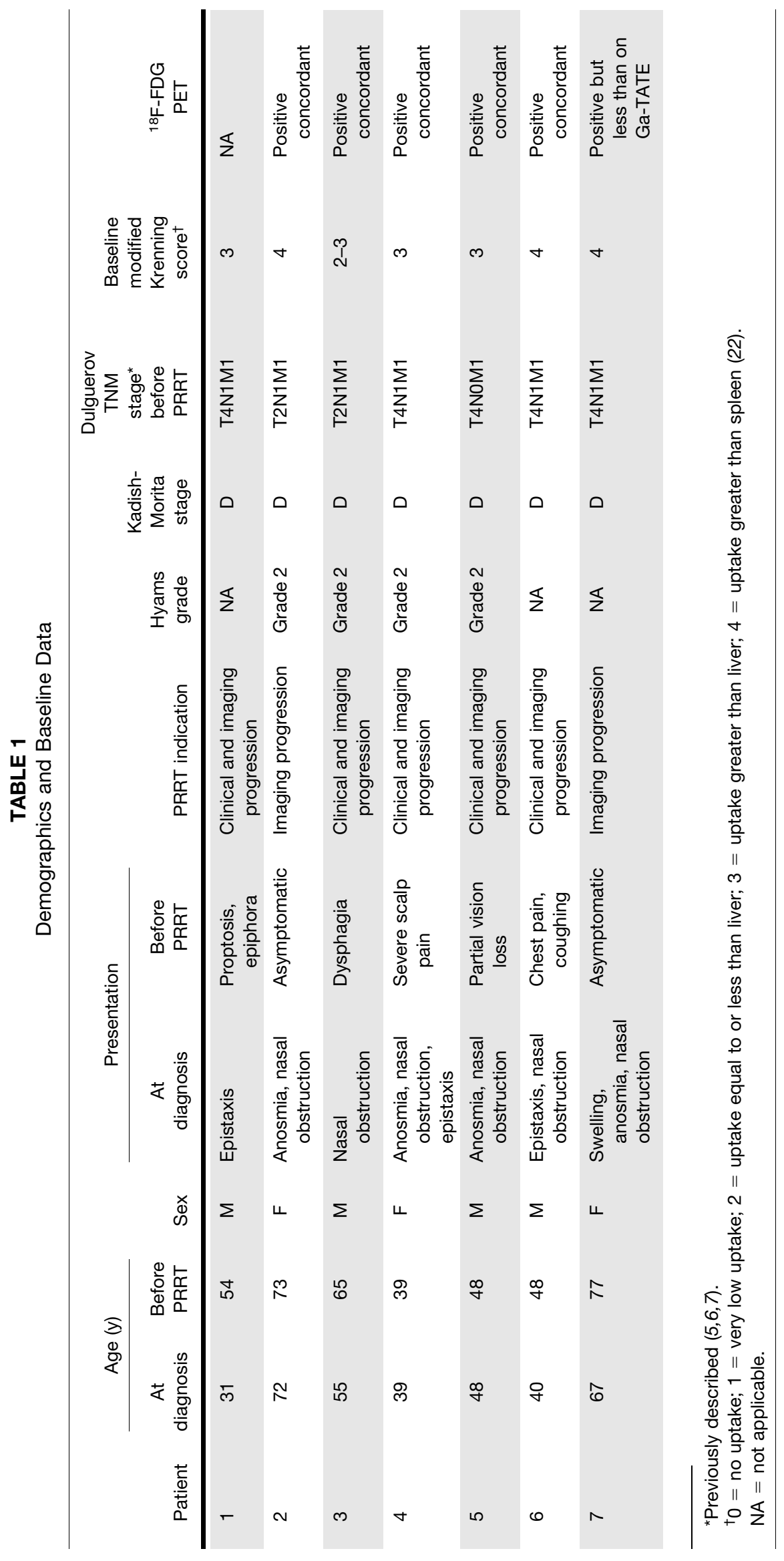

PRRT EFFiCACY FOR ESTHESIONEUROBLASTOMA - Kamel Hasan et al. 
TABLE 2

Peptide Receptor Radionuclide Therapy (PRRT) Details

\begin{tabular}{|c|c|c|c|}
\hline & Induction/maintenance PRRT & Total cumulative activity & $\begin{array}{l}\text { PRRT-related clinical/blood } \\
\text { adverse events }\end{array}$ \\
\hline Patient 1 & $\begin{array}{l}4 \text { cycles between Sep. } 2008 \text { and Feb. } 2009 \\
\text { of }{ }^{111} \text { In-octreotide and }{ }^{177} \text { Lu-octreotate with } \\
5 \text {-FU*/1 cycle March } 2010 \text { of }{ }^{111} \text { In-octreotide } \\
\text { with 5-FU }\end{array}$ & $\begin{array}{l}13.9 \mathrm{GBq}^{\dagger}{ }^{111} / \mathrm{n} \text {-octreotide; } \\
24.7 \mathrm{GBq}^{177} \mathrm{Lu} \text {-octreotate }\end{array}$ & Transient phlebitis/none \\
\hline Patient 2 & $\begin{array}{l}3 \text { cycles between May and Sep. } 2010 \text { of } \\
{ }^{111} \text { In-octreotide and }{ }^{177} \text { Lu-octreotate with 5-FU/4 } \\
\text { cycles between Dec. } 2011 \text { and Jul. } 2014 \\
\text { of }{ }^{177} \text { Lu-octreotate and }{ }^{90} \text { Y-octreotate }\end{array}$ & $\begin{array}{l}15.2 \mathrm{GBq}{ }^{111} \mathrm{In} \text {-octreotate; } 33.5 \mathrm{GBq} \\
{ }^{177} \mathrm{Lu} \text {-octreotate; } 1.1 \mathrm{GBq} \\
{ }^{90} \mathrm{Y} \text {-octreotate }\end{array}$ & $\begin{array}{l}\text { None/grade } 2^{\ddagger} \\
\text { thrombocytopenia }\end{array}$ \\
\hline Patient 3 & $\begin{array}{l}2 \text { cycles between Nov. } 2012 \text { and Jan. } 2013 \\
\text { of }{ }^{111} \text { In-octreotide and }{ }^{177} \text { Lu-octreotate }\end{array}$ & $\begin{array}{l}13 \mathrm{GBq}{ }^{177} \mathrm{Lu} \text {-octreotate; } 12.6 \\
\mathrm{GBq}{ }^{111} \mathrm{In} \text {-octreotate }\end{array}$ & $\begin{array}{l}\text { Pneumonia/grade } 4 \\
\text { neutropenia }\end{array}$ \\
\hline Patient 4 & $\begin{array}{l}4 \text { cycles between Jan. and Jul. } 2017 \text { of } \\
177 \text { Lu-octreotate with etoposide }\end{array}$ & $24.9 \mathrm{GBq}{ }^{177} \mathrm{Lu}$-octreotate & None/none \\
\hline Patient 5 & $\begin{array}{l}3 \text { cycles between Nov. } 2017 \text { and Feb. } 2018 \\
\text { of }{ }^{177} \text { Lu-octreotate and }{ }^{90} \text { Y-octreotate }\end{array}$ & $\begin{array}{l}22.0 \mathrm{GBq}{ }^{177} \mathrm{Lu} \text {-octreotate; } 3.2 \mathrm{GBq} \\
{ }^{90} \mathrm{Y} \text {-octreotate }\end{array}$ & $\begin{array}{l}\text { Recurrence of cerebrospinal } \\
\text { fluid leak/none }\end{array}$ \\
\hline Patient 6 & $\begin{array}{l}4 \text { cycles between Feb. and Jul. } 2015 \text { of } \\
{ }^{177} \text { Lu-octreotate/3 salvage cycles } \\
\text { between Jan. and Apr. } 2017 \text { of }{ }^{177} \text { Lu-octreotate }\end{array}$ & $53.3 \mathrm{GBq}{ }^{177} \mathrm{Lu}$-octreotate & $\begin{array}{l}\text { Weakness and SOB/transient } \\
\text { G1-2 pancytopenia }\end{array}$ \\
\hline Patient 7 & $\begin{array}{l}3 \text { cycles between Jun. and Aug. } 2018 \\
\text { of }{ }^{177} \text { Lu-octreotate }\end{array}$ & $22.1 \mathrm{GBq}^{177} \mathrm{Lu}$-octreotate & Mild hair loss/none \\
\hline $\begin{array}{l}{ }^{\star} 5 \mathrm{FU}=5 \\
{ }^{\dagger} \mathrm{GBq}=\mathrm{G} \\
{ }^{{ }} \mathrm{CTCAE} 5 . \\
\mathrm{NA}=\text { not }\end{array}$ & $\begin{array}{l}\text { racil. } \\
\text { uerel. } \\
\text { mon Terminology Criteria for Adverse Events). } \\
\text { le. }\end{array}$ & & \\
\hline
\end{tabular}

measured using a composite reference of both molecular and anatomic imaging, with the former assessed by the number and intensity of lesions (using a modified Krenning score related to tomographic rather than planar imaging) and the latter as defined by RECIST 1.1. Progression-free survival was calculated from PRRT initiation to tumor progression or death from any cause and was defined by symptomatic or imaging progression. Overall survival was defined from PRRT initiation to death from any cause. Toxicity was defined by the Common Terminology Criteria for Adverse Events, version 5.0.

All patients provided written informed consent for PRRT under compassionate-use authority. Retrospective analysis and reporting of results were granted a patient-consent waiver by the ethical committees

TABLE 3

Peptide Receptor Radionuclide Therapy (PRRT) Outcomes

\begin{tabular}{|c|c|c|c|c|c|}
\hline & $\begin{array}{c}3 \text { months post PRRT clinical/ } \\
\text { imaging }\left({ }^{68} \mathrm{Ga} \text {-DOTATATE }\right. \\
\text { scan) response }\end{array}$ & $\begin{array}{l}\text { Further follow up/diseases } \\
\text { course }\end{array}$ & $\begin{array}{l}\text { Overall clinical/ } \\
\text { imaging response } \\
\text { to PRRT }\end{array}$ & PFS (mo) & Overall survival (mo) \\
\hline Patient 1 & $\begin{array}{l}\text { Improvement in bilateral } \\
\text { proptosis/partial response }\end{array}$ & $\begin{array}{l}\text { Eventual progression with near- } \\
\text { complete blindness; denied any } \\
\text { further intervention; Nov. 2011: } \\
\text { succumbed to his illness }\end{array}$ & Partial/partial & 17 & 38 \\
\hline Patient 2 & $\begin{array}{l}\text { No significant complaints/ } \\
\text { minimal improvement }\end{array}$ & $\begin{array}{l}\text { Remarkable response after } \\
\text { maintenance cycles; Oct. 2014: } \\
\text { died of coronary artery disease }\end{array}$ & Stable/partial & 30 & 53 \\
\hline Patient 3 & Progression/not available ${ }^{\star}$ & $\begin{array}{l}\text { No more PRRT offered; failed further } \\
\text { chemotherapy; May 2013: } \\
\text { succumbed to his illness }\end{array}$ & Progression/progression & 0 & 4 \\
\hline Patient 4 & $\begin{array}{l}\text { Complete resolution of scalp } \\
\text { pain/stable disease }\end{array}$ & Ongoing response & Complete/stable & No progression & Alive (33) \\
\hline Patient 5 & NA & $\begin{array}{l}\text { Marked clinical improvement with } \\
\text { ceasing cerebrospinal fluid leak; } \\
\text { local tumor regression by imaging }\end{array}$ & Partial/partial & 17 & 20 \\
\hline Patient 6 & $\begin{array}{l}\text { Improvement in bilateral } \\
\text { proptosis/partial response }\end{array}$ & $\begin{array}{l}\text { Eventual progression after } 8 \mathrm{mo} \text {; June } \\
\text { 2018: succumbed to his illness }\end{array}$ & Partial/partial & 20 & 32 \\
\hline Patient 7 & $\begin{array}{l}\text { No significant complaints/ } \\
\text { minimal improvement }\end{array}$ & Ongoing response & Stable/partial & No progression & Alive (11) \\
\hline
\end{tabular}

${ }^{*}$ Patient underwent only ${ }^{18} \mathrm{~F}-\mathrm{FDG} \mathrm{PET} / \mathrm{CT}$, which showed marked progression of disease.

$\mathrm{NA}=$ not applicable. 


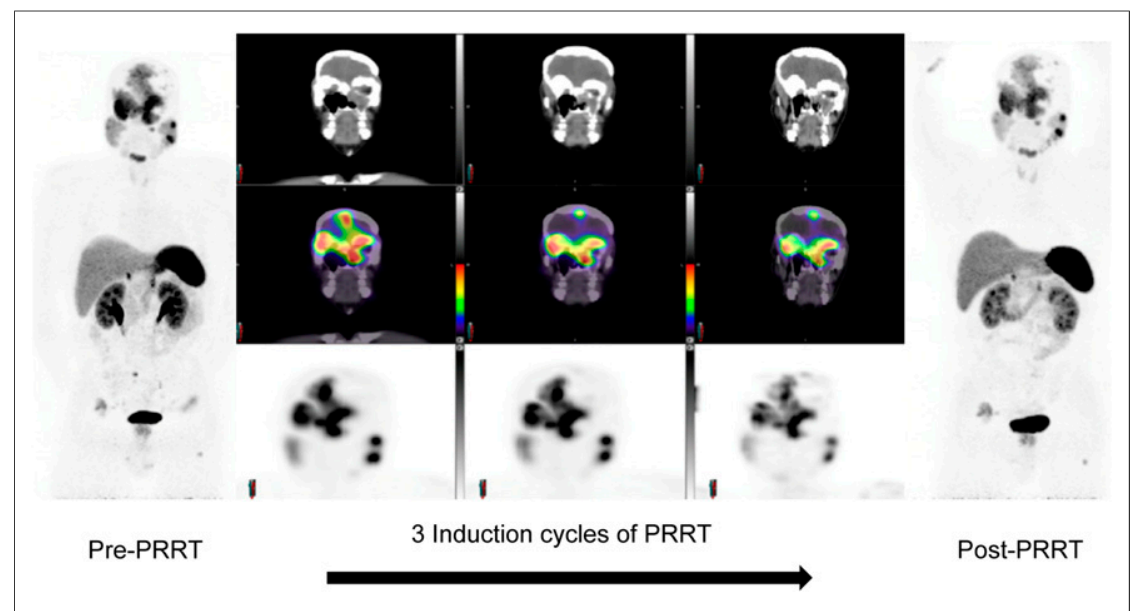

FIGURE 1. Patient 1: locally extensive disease involving sinuses and orbit with brain metastases and partial response to PRRT after 3 induction cycles of ${ }^{177} \mathrm{Lu}$-DOTATATE. Shown are ${ }^{68} \mathrm{Ga}-$ DOTATATE before PRRT (left) and after PRRT (right) and CT, fused, and posttherapy SPECT scans (middle, from left to right).

of Peter MacCallum Cancer Centre and Hadassah-Hebrew University Medical Center.

\section{RESULTS}

Database review identified 7 patients who were treated with PRRT (4 men, 3 women; 39-77 y old). All patients had Kadish stage D disease; The Hyams grade was II in 4 patients.

Four patients had high-volume and 3 had small- to moderatevolume disease, either locally advanced or metastatic. All had prior (sometimes repeated) conventional multimodality treatment, including surgery, chemotherapy, and radiation therapy. One had a remarkable response and remained relatively asymptomatic early in the course of disease; 3 had favorable partial responses both clinically and by imaging; 2 had disease stabilization by imaging (1 patient had a marked clinical response with complete resolution of headaches); and 1 had locoregional recurrence involving the retropharyngeal region, which progressed shortly after PRRT. Details of the disease course and therapy are presented in Tables 1 and 2, and examples of multimodality scans are shown in Figures 1-4.

Five patients died, 4 secondary to esthesioneuroblastoma. The median progression-free survival was $17 \mathrm{mo}$ (range, 0-30 mo), and the median overall survival was $32 \mathrm{mo}$ (range, 4-53 mo). Two patients are still alive at 33 and 11 mo of follow-up.

The toxicity of PRRT was generally mild but included 1 case each of transient grade 4 neutropenia (in the context of prior chemotherapy), grade 2 thrombocytopenia, and a transient grade 1-2 pancytopenia. These were likely multifactorial and related to multiple previous therapies, as the hemotoxicity of PRRT is known to usually be

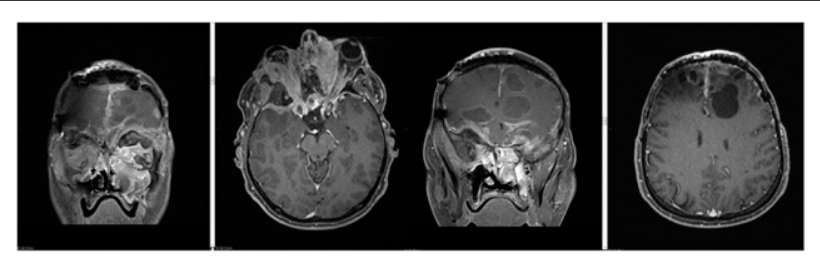

FIGURE 2. Patient 1: contrast-enhanced T1-weighted MRI sections of head, brain metastases, and local disease. Patient experienced subsequent progression with orbital, maxillary, and base-of-skull extension. transient and of low grade (16). One patient developed worsening of his preexisting tumorrelated cerebrospinal fluid leak, secondary to measurable shrinkage of tumor, which extended intracranially through the dura.

\section{DISCUSSION}

Treatment of unresectable recurrent or metastatic esthesioneuroblastoma remains challenging, with limited therapeutic options. High SSR expression in some of these tumors makes a theranostics approach using PRRT a therapeutic option. Outside this series, there have been only 3 single esthesioneuroblastoma cases treated with PRRT reported in the literature, with dates ranging from 2015 to 2018 (17-19). Our first patient was treated in 2008 at the Peter MacCallum Cancer Centre. Our series encompasses complicated and heterogeneous clinical presentations and disease courses. For most patients, PRRT was able to achieve favorable clinical and imaging responses despite progression after conventional therapies. Treatment was generally well tolerated, without significant toxicity.

The single patient with progressive disease in our series may have had a particularly poor outcome for several reasons. External-beam radiation therapy in our experience diminishes subsequent local PRRT response, possibly secondary to radiation-induced vasculopathy with eventual compromise to lesional blood flow or selection for radioresistant disease clones (20). This may partly explain the poor response despite high SSR expression. Additionally, patients with esthesioneuroblastoma who develop retropharyngeal nodal metastasis are known to have a poorer prognosis $(18,19,21)$.

Esthesioneuroblastoma is a rare entity, and collecting data is challenging. Although on a very limited series, this study is, to our knowledge, the only one to report outcomes of PRRT in a consecutive cohort of patients. A further limitation is the retrospective nature of the study, with nonuniform PRRT protocols and prior therapies reflecting different institutional practices. Furthermore, variability in administered activity, number of cycles, and use of radiosensitizing chemotherapy reflecting personalized treatment regimens may limit the generalizability of results.

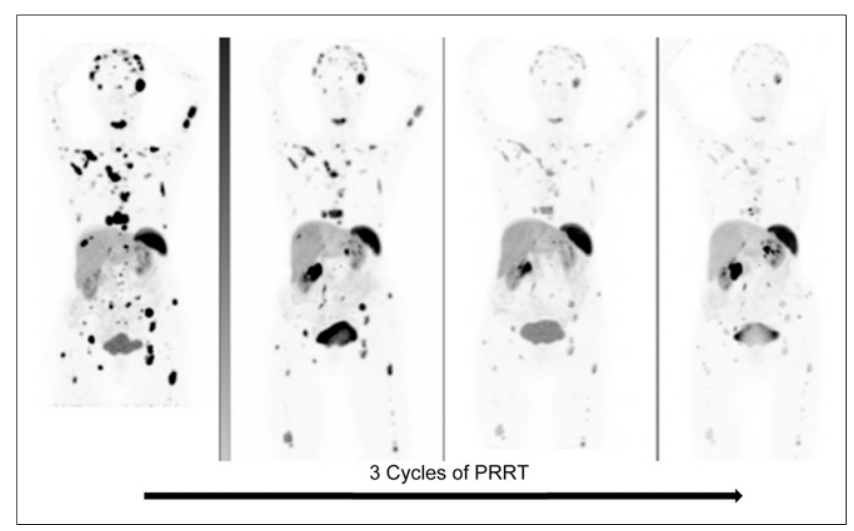

FIGURE 3. Patient 2: multiple-time-point ${ }^{68} \mathrm{Ga}$-DOTATATE scans showing multiple metastatic deposits involving both axial and appendicular skeleton. Patient showed remarkable response to PRRT after 3 cycles of ${ }^{177}$ Lu-DOTATATE. 


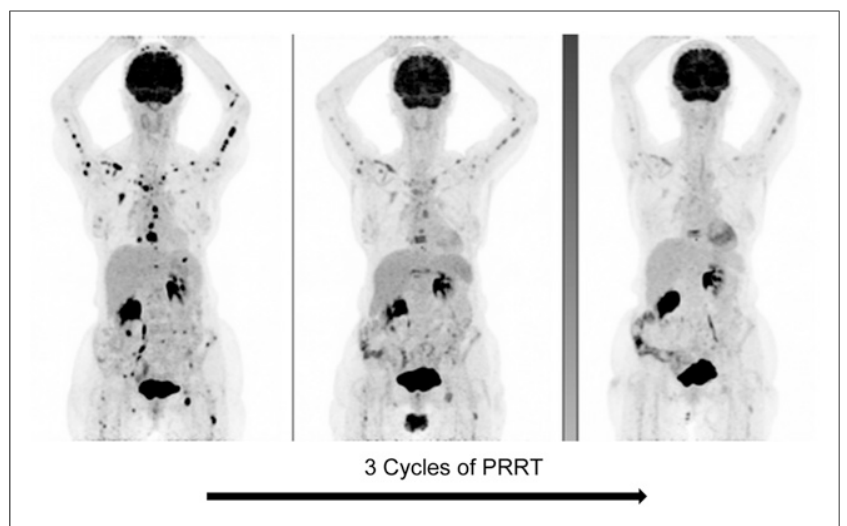

FIGURE 4. Patient 2: multiple-time-point ${ }^{18} \mathrm{~F}-\mathrm{FDG}$ PET/CT. Patient showed concordant remarkable response to PRRT after 3 cycles of 177Lu-DOTATATE and no disease discordance.

\section{CONCLUSION}

PRRT with radiolabeled somatostatin analogs appears to be a safe and effective option for unresectable, locally extensive, or metastatic esthesioneuroblastoma. Case selection depends on symptoms, SSR expression, disease volume, and prior intervention. In our limited series, PRRT improved symptoms and provided promising disease control and encouraging survival duration. Further prospective studies incorporating formal quality-of-life assessments and standardized response assessment are warranted.

\section{DISCLOSURE}

No potential conflict of interest relevant to this article was reported.

\section{KEY POINTS}

QUESTION: Is PRRT effective for unresectable metastatic esthesioneuroblastoma?

PERTINENT FINDINGS: This study was a retrospective caseseries review. PRRT shows promising efficacy and moderate survival duration in unresectable locally advanced or metastatic esthesioneuroblastoma, warranting larger cohort studies incorporating measures of quality of life.

IMPLICATIONS FOR PATIENT CARE: PRRT shows potential for use in the treatment of esthesioneuroblastoma patients.

\section{REFERENCES}

1. Jethanamest D, Morris LG, Sikora AG, Kutler DI. Esthesioneuroblastoma. Arch Otolaryngol Head Neck Surg. 2007;133:276-280.

2. Thompson LD. Olfactory neuroblastoma. Head Neck Pathol. 2009;3:252-259.
3. Bell D, Saade R, Roberts D, et al. Prognostic utility of Hyams histological grading and Kadish-Morita staging systems for esthesioneuroblastoma outcomes. Head Neck Pathol. 2015;9:51-59.

4. Hyams VJ. Olfactory neuroblastoma (case 6). In: Batsakis JG, Hyams VJ, Morales AR, eds. Special Tumors of the Head and Neck. Chicago, IL: ASCP Press; 1982:24-29.

5. Kadish S, Goodman M, Wang CC. Olfactory neuroblastoma: a clinical analysis of 17 cases. Cancer. 1976;37:1571-1576.

6. Morita A, Ebersold MJ, Olsen KD, Foote RL, Lewis JE, Quast LM. Esthesioneuroblastoma: prognosis and management. Neurosurgery. 1993;32:706714

7. Dulguerov P, Allal AS, Calcaterra TC. Esthesioneuroblastoma: a meta-analysis and review. Lancet Oncol. 2001;2:683-690.

8. Bachar G, Goldstein DP, Shah M, et al. Esthesioneuroblastoma: the Princess Margaret Hospital experience. Head Neck. 2008;30:1607-1614.

9. Chamberlain MC. Treatment of intracranial metastatic esthesioneuroblastoma. Cancer. 2002;95:243-248.

10. Marinelli JP, Janus JR, Van Gompel JJ, et al. Esthesioneuroblastoma with distant metastases: systematic review \& meta-analysis. Head Neck. 2018;40: 2295-2303.

11. Hofman MS, Kong G, Neels OC, et al. High management impact of Ga-68 DOTATATE (GaTate) PET/CT for imaging neuroendocrine and other somatostatin expressing tumours. J Med Imaging Radiat Oncol. 2012;56:4047.

12. Rostomily RC, Elias M, Deng M, et al. Clinical utility of somatostatin receptor scintigraphic imaging (OctreoScan) in esthesioneuroblastoma: a case study and survey of somatostatin receptor subtype expression. Head Neck. 2006;28: 305-312.

13. Koukouraki S, Strauss LG, Georgoulias V, et al. Evaluation of the pharmacokinetics of ${ }^{68} \mathrm{Ga}$-DOTATOC in patients with metastatic neuroendocrine tumours scheduled for ${ }^{90}$ Y-DOTATOC therapy. Eur J Nucl Med Mol Imaging. 2006;33: $460-466$.

14. Hofman MS, Lau WF, Hicks RJ. Somatostatin receptor imaging with ${ }^{68} \mathrm{Ga}$ DOTATATE PET/CT: clinical utility, normal patterns, pearls, and pitfalls in interpretation. Radiographics. 2015;35:500-516.

15. Hicks RJ, Kwekkeboom DJ, Krenning E, et al. ENETS consensus guidelines for the standards of care in neuroendocrine neoplasia: peptide receptor radionuclide therapy with radiolabeled somatostatin analogues. Neuroendocrinology. 2017;105: 295-309.

16. Strosberg J, El-Haddad G, Wolin E, et al. NETTER-1 Trial Investigators. Phase 3 trial of ${ }^{177} \mathrm{Lu}$-dotatate for midgut neuroendocrine tumors. N Engl J Med. 2017;376: $125-135$.

17. Makis W, Mccann K, Mcewan AJ. Esthesioneuroblastoma (olfactory neuroblastoma) treated with ${ }^{111}$ In-octreotide and ${ }^{177} \mathrm{Lu}$-DOTATATE PRRT. Clin Nucl Med. 2015;40:317-321.

18. Sabongi JG, Gonçalves MC, Alves CD, Alves J, Scapulatempo-Neto C, Moriguchi SM. Lutetium 177-DOTA-TATE therapy for esthesioneuroblastoma: a case report. Exp Ther Med. 2016;12:3078-3082.

19. Schneider JR, Shatzkes DR, Scharf SC, et al. Neuroradiological and neuropathological changes after ${ }^{177} \mathrm{Lu}$-octreotate peptide receptor radionuclide therapy of refractory esthesioneuroblastoma. Oper Neurosurg (Hagerstown). 2018;15:100109.

20. Park HJ, Griffin RJ, Hui S, Levitt SH, Song CW. Radiation-induced vascular damage in tumors: implications of vascular damage in ablative hypofractionated radiotherapy (SBRT and SRS). Radiat Res. 2012;177:311-327.

21. Rinaldo A, Ferlito A, Shaha AR, Wei WI, Lund VJ. Esthesioneuroblastoma and cervical lymph node metastases: clinical and therapeutic implications. Acta Otolaryngol. 2002;122:215-221.

22. Krenning EP, Valkema R, Kooij PP, et al. Scintigraphy and radionuclide therapy with [indium-111-labelled-diethyl triamine penta-acetic acid-D-Phe1]octreotide. Ital J Gastroenterol Hepatol. 1999;31(suppl 2):S219-S223. 